\title{
Desigualdades de gênero em tempo de trabalho pago e não pago no Brasil, 2013
}

Marcelo Medeiros

\& Luana Simões Pinheiro*

Resumo: Avalia-se a desigualdade de gênero no uso do tempo para trabalho no Brasil dividindo-se o tempo total de trabalho em trabalho pago (mercado) e não pago (doméstico) a partir de dados da Pnad 2013. Conclui-se que há muita desigualdade dentro do grupo dos homens bem como dentro do grupo das mulheres. A maior parte da desigualdade dentro desses grupos está associada à polarização entre trabalhar ou não. Os trabalhos femininos, pago e não pago, são os que mais contribuem para a desigualdade total na sociedade. O trabalho doméstico masculino não é frequente e por isso contribui pouco para a desigualdade. Os principais determinantes do diferencial de gênero na duração das jornadas de trabalho são a proporção de pessoas que fazem trabalho pago e a duração do trabalho não pago. A divisão sexual do trabalho não é caracterizada por um espelhamento de atividades e, por isso, as mulheres invariavelmente trabalham mais que os homens, mesmo quando as desigualdades dentro dos grupos são consideradas.

palavras-chave: uso do tempo, trabalho doméstico, divisão sexual do trabalho.

\section{Introdução}

A forma como as pessoas conseguem alocar seu tempo em diferentes atividades determina em boa medida o que são capazes de fazer e como podem se beneficiar dos frutos de seus esforços. Particularmente importante é a alocação de tempo em trabalho, remunerado ou não, uma vez que essa é a atividade que, de maneira geral, envolve a maior parcela do tempo das pessoas ao longo de sua vida adulta. O tempo de trabalho está associado, primeiro, a responsabilidades (quem e quanto deve ser assumido de certas tarefas) e, segundo, a poderes (quem controla o que a partir dos resultados do trabalho). Não é difícil, portanto, ver porque o uso do tempo para trabalho é uma questão-chave para se entender o funcionamento da sociedade.

O uso do tempo em trabalho é especialmente relevante para o estudo das desigualdades de gênero. Mulheres e homens não trabalham igualmente nas mesmas atividades, nem o fazem na mesma duração. Logo, responsabilidades e poderes são diferentes entre homens e mulheres, em parte como decorrência da forma como alocam seu tempo.

\footnotetext{
* Marcelo Medeiros é doutor pela Universidade de Brasília (UnB), realiza estudos no campo sobre a desigualdade social, tem formação em sociologia e economia, atualmente é visitante na Yale Law School, New Haven (CT), USA. É também pesquisador do Ipea e professor na UnB, Brasília (DF), Brasil,. <marcelo.medeiros@ ipea.gov.br>.

Luana Simões Pinheiro é doutoranda em sociologia pela Universidade de Brasília (UnB), Brasília (DF), Brasil, é economista e mestre em sociologia pela mesma instituição. É também técnica de planejamento e pesquisa do Instituto de Pesquisas Econômicas Aplicadas (Ipea). <luana.pinheiro@ gmail.com>.
} 
Para analisar essa alocação, avaliamos a desigualdade de gênero no uso do tempo para trabalho no Brasil. Dividimos o tempo total de trabalho em tempo de trabalho pago (aquele que é realizado no mercado de trabalho e na produção para o autoconsumo) e tempo de trabalho não pago (trabalho doméstico). Nosso objetivo é mensurar a carga de cada tipo de trabalho e o grau de desigualdade dessa carga entre mulheres e homens, bem como dentro desses grupos. Para isso, lançamos mão de ferramentas que são utilizadas nas pesquisas sobre desigualdade de renda e as aplicamos aos dados da Pesquisa Nacional por Amostra de Domicílios (Pnad) de 2013.

Parte do que estamos estudando é senso comum. Por exemplo, é óbvio que existe uma divisão sexual do trabalho e que nessa divisão a maior responsabilidade pelo trabalho doméstico é feminina. Nosso foco, porém, não é na constatação desses fatos e sim em sua mensuração com alguma precisão. Esse tipo de mensuração é especialmente importante para nossos objetivos, uma vez que nos importa não somente comparar uma categoria geral de mulheres com outra de homens e sim verificar também diferenças que existem dentro dos grupos formados pelas mulheres e pelos homens.

Especificamente, nos interessa saber:

i. em que medida a divisão sexual do trabalho no Brasil se caracteriza por um espelhamento das jornadas de trabalho pago e não pago de homens e mulheres, ou seja, em que medida a menor participação de homens em trabalho não pago e sua maior presença em trabalho pago seria compensada pelo envolvimento das mulheres em sentido oposto: maior presença em trabalho não pago e menor em trabalho pago;

ii. o quanto o acúmulo de jornadas de trabalho implica desigualdades de gênero na carga total de trabalho, entendida esta como a soma do tempo em trabalho pago e em trabalho não pago;

iii. qual é o nível de desigualdade no uso do tempo para cada tipo de trabalho, segundo o sexo; e

iv. qual a contribuição de cada tipo de trabalho para essa desigualdade.

Nossas conclusões gerais são de que metade, tanto das mulheres como dos homens, não acumula duas jornadas de trabalho; os principais determinantes do diferencial de gênero na duração das jornadas de trabalho são a proporção de pessoas que fazem trabalho pago e a duração do trabalho não pago; os homens e as mulheres 
constituem grupos internamente heterogêneos, com a maior parte da desigualdade dentro desses grupos sendo associada à polarização entre trabalhar ou não em determinada atividade.

Em relação à desigualdade total de tempo de trabalho, investigamos como cada tipo de trabalho, desempenhado por cada sexo, contribuiria para a sua conformação. Desigualdade total é aquela que se refere à desigualdade na distribuição do tempo de trabalho total (soma dos tempos pago e não pago) da população total (homens e mulheres). Nesse caso, é o trabalho pago das mulheres aquele que mais contribui para a desigualdade total de tempo de trabalho, seguido do trabalho pago dos homens e do não pago das mulheres, sendo o trabalho não pago dos homens de pouca relevância em função de sua baixa ocorrência e curta duração.

Finalmente, concluímos que a divisão sexual do trabalho não é caracterizada apenas por um espelhamento de atividades pagas e não pagas entre homens e mulheres, e isso está relacionado ao fato de as jornadas totais de trabalho de mulheres e homens serem próximas, mas as mulheres, invariavelmente, trabalham mais quando comparadas com homens que seriam seus equivalentes na distribuição de tempo, as mulheres sempre apresentarão jornadas maiores que os homens. Equivalentes, neste caso, refere-se à posição dos homens e das mulheres na distribuição de tempo de trabalho total de cada sexo (décimos, centésimos, ou qualquer outro ponto de corte).

\section{Estudos antecedentes}

A maior parte das pesquisas sobre uso do tempo vem de países da Europa Ocidental, da Austrália ou dos Estados Unidos, que já contam com pesquisas de uso do tempo estruturadas e de longa data, permitindo mesmo a realização de análises longitudinais. Essas pesquisas têm apontando para uma redução significativa do tempo feminino alocado no trabalho doméstico e para uma ampliação suave do tempo masculino nas mesmas atividades. A despeito deste movimento, identificam que o trabalho doméstico permanece feminino e que, embora a contribuição relativa dos homens tenha aumentado, as mulheres fazem, ainda, pelo menos duas vezes mais trabalho doméstico do que eles (Bianchi et alii, 2000; Brines, 1994; Coltrane, 2000; Fuwa, 2004; Greenstein, 2000).

No entanto, para além da desigual distribuição do trabalho reprodutivo, os estudos apontam para uma segmentação das tarefas realizadas no âmbito domiciliar. As mulheres tornam-se responsáveis por atividades que poderiam ser identificadas como rotineiras e menos discricionárias (ou seja, com menos possibilidades de se- 
1. Para uma discussão mais detalhada sobre estas perspectivas, ver Luana Pinheiro, "Determinantes da alocação de tempo em trabalho reprodutivo: uma revisão sobre os achados em pesquisas nacionais e internacionais", in $\mathrm{N}$. Fontoura \& C. Araujo (2016).

2. A grande maioria dos estudos conduzidos refere-se a casais heterossexuais apenas, seja pela limitação de informações, seja pela reprodução de um modelo tradicional dominante de família. Poucos estudos têm focado suas análises em domicílios não formados por casais ou por famílias homoafetivas, valendo destacar que estes esforços têm crescido ao longo dos últimos anos (ver, por exemplo, Baxter, 2005; Giddings, 1998; Kurdek, 1993; Natalier, 2003; South \& Spitze, 1994; Van Every, 1997). rem adiadas), tais como lavar roupas e vasilhas, passar roupas, limpar a casa, cuidar dos filhos, cozinhar, as quais também seriam tarefas muito consumidoras de tempo. Já aos homens caberiam as atividades mais ocasionais e flexíveis, a exemplo de pequenos reparos nas residências, cuidar do jardim, cuidar dos carros ou pagar contas (Coltrane, 2000; Fuwa, 2004; Lennon \& Rosenfield, 1994).

Esses estudos tratam de temas diversos, mas suas conclusões convergentes são as seguintes:

i. o tempo econômico masculino é maior do que o tempo feminino e, contrariamente, o tempo feminino na reprodução social é maior do que o masculino; e

ii. o aumento da jornada de tempo econômico prejudica mais as muIheres, uma vez que o tempo dedicado por elas à reprodução social não tende a diminuir, o que leva a uma redução no tempo livre das mulheres, que acabam por adicionar tempo econômico ao tempo da reprodução.

Uma parte expressiva dos estudos produzidos no cenário internacional procura identificar o que, de fato, determina a alocação de tempo em trabalho não pago. Tais determinantes podem ser agrupados em quatro grandes abordagens ${ }^{1}$ :

- Recursos relativos/teoria da dependência econômica: fundamenta-se na visão das trocas econômicas ou em teorias conhecidas como teorias da barganha. A ideia é que a divisão de trabalho doméstico não remunerado, por ser atividade indesejada, é vista como resultado de negociações entre os membros do domicílio (maridos e mulheres) $)^{2}$, que, a partir dos insumos e produtos que trazem ao casamento, procuram encontrar o melhor acordo baseado em interesses estritamente individuais. O nível de recursos relativos - ou de dependência econômica - leva ao estabelecimento de relações que determinam o quanto de trabalho doméstico será realizado por cada membro do casal. Aquele com mais recursos, utiliza sua vantagem para evitar realizar trabalho doméstico e fazer com que o cônjuge o faça. O tempo em trabalho doméstico reflete, nesta perspectiva, relações de poder que se estabelecem entre homens e mulheres. Esta perspectiva adere à visão de que a relação por trás da divisão do trabalho doméstico é fundamentalmente econômica e, portanto, neutra em relação a gênero. Uma série de estudos, porém, tem apontado limites ao nível de efetividade que esta perspectiva pode ter, especialmente para as mulheres. Becker 
(1991), Brines (1994) e Greenstein (2000) encontraram, por exemplo, que homens dependentes economicamente fazem menos trabalho reprodutivo quanto mais dependentes forem de suas esposas, o que é exatamente o oposto do que prevê a teoria da dependência.

- Tempo disponível: nesta perspectiva, a alocação de tempo em trabaIho doméstico é racionalmente realizada de acordo com a disponibilidade do tempo das pessoas do domicílio e a quantidade de trabalho doméstico a ser feita. Nesse sentido, a pessoa com maior tempo livre tomaria uma "decisão racional" de assumir a responsabilidade pelas tarefas domésticas e de cuidados. Esta perspectiva implica que deve existir uma forte associação entre o número de horas que as mulheres e os homens trabalham no mercado e o número de horas que trabaIham em casa e que também deve haver uma relação positiva entre emprego/horas de trabalho no mercado das mulheres e horas - ou proporção - de trabalho doméstico dos homens. Esta vertente teórica, assim como a anterior, pressupõe neutralidade de gênero. No entanto, ainda que existam evidências, tanto para homens como para mulheres, de que o tempo de trabalho no mercado tem impactos negativos sobre o tempo de trabalho doméstico, diversos estudos têm apontado que as mulheres continuam responsáveis pela maior carga de trabalho não pago, independentemente da fração de tempo em trabalho pago pela qual elas respondam no âmbito do casal, sendo necessário, portanto, avançar em busca de outros determinantes que expliquem as desigualdades de gênero.

- Ideologia de gênero: esta abordagem defende que a alocação de tempo em trabalho reprodutivo está relacionada a uma questão simbólica vinculada às relações de gênero e argumenta que não há um simples trade-off entre tempo gasto no mercado e tempo gasto em trabalho doméstico ou uma relação direta entre renda (relativa ou absoluta) e tempo em trabalho não pago. A ideia por trás destes argumentos é que a realização de trabalho doméstico expressa identidades, normas, interações e instituições. Homens e mulheres socializados segundo papéis tradicionais de gênero tendem a dividir o trabalho doméstico de acordo com essa socialização. Cria-se, assim, uma regra cultural implícita, na qual o trabalho reprodutivo torna-se uma atividade predominantemente feminina.

- Ciclos de vida: esta abordagem trata do impacto no trabalho reprodutivo de fatores como idade, experiência no mundo do trabalho, 
arranjos familiares, transições familiares, casamento e recasamento, fertilidade e sexualidade. Esta categoria traz um grande conjunto de hipóteses e não um corpo único teórico. Entre estas hipóteses, destacam-se:

a. casamentos e filhos aumentam o trabalho doméstico não remunerado das mulheres, mais do que dos homens;

b. casais de mesmo sexo ou grupos de pessoas que coabitam (sem casamento legal) tendem a dividir mais o trabalho reprodutivo do que casais heterossexuais, uma vez que se espera desses grupos uma menor resignação às normas do casamento tradicional e que persigam ideais de vida mais igualitários;

c. a existência de filhos mais jovens tende a aumentar a demanda por trabalho doméstico (especialmente para as mulheres), mas a presença de filhos mais velhos aumenta a possibilidade de divisão do trabalho doméstico, especialmente se forem meninas. É interessante notar que esta perspectiva considera que trabalhar de forma isolada com variáveis demográficas - como idade, sexo, estado civil etc. - traz uma série de limitações à análise, uma vez que a idade biológica, por exemplo, só terá significado real quando analisada em conjunto com o sexo do indivíduo e seu estado civil, assim como o estado civil só é uma variável relevante para a análise, quando conjugado à presença e ao número de filhos.

Importante destacar que estas abordagens não são excludentes, pelo contrário, tendem a se reforçar e a se fortalecer mutuamente, ainda que, em geral, os estudos tenham apontado para o maior peso da perspectiva de gênero nesta definição. Segundo Scott Coltrane (2000), todas essas perspectivas assumem que o trabalho reprodutivo é percebido como atividade indesejável e que homens e mulheres tentam, assim, minimizar a quantidade de tempo nele despendida.

Os resultados apresentados pelos estudos produzidos baseiam-se, geralmente, em algum indicador sintético de todo o grupo, por exemplo, o conjunto dos homens ou das mulheres. Análises específicas sobre desigualdades na distribuição de tempo dentro dos grupos são menos frequentes, mas há exemplos, como o estudo sobre a distribuição do tempo de trabalho na Bolívia (Medeiros, Costa \& Osorio, 2010). Ao empregar técnicas semelhantes às utilizadas neste artigo, o estudo concluiu que, de maneira geral, as mulheres bolivianas trabalham mais do que os homens, mas a despeito de uma clara divisão sexual do trabalho, existe também forte heterogeneidade dentro dos grupos. A divisão sexual do trabalho, na Bolívia, é marcada principalmen- 
te por diferenças de gênero na duração do trabalho pago e não pago, mais do que na incidência deste tipo de atividade em cada grupo. Existe uma substituição parcial entre trabalho pago e não pago, ou seja, quando a jornada se amplia para um, reduz-se a do outro. Não há, porém, substituição completa entre estas atividades, o que faz com que as mulheres tendam a acumular uma dupla jornada de trabalho.

Para o caso brasileiro, contudo, ainda há pouca produção no campo. Dois estudos pioneiros, abriram espaço para a temática no país: o de Amaury de Souza (1976), implementado no estado da Guanabara, na década de 1970, e o de Neuma Aguiar (2001), realizado em Belo Horizonte, no final dos anos 1990. Ambos foram conduzidos a partir da metodologia de diários e permitiram mensurar, pela primeira vez, as jornadas cotidianas em diferentes atividades. O estudo de Souza limitou-se à Guanabara ao passo que o de Aguiar à região metropolitana de Belo Horizonte. Ambos encontraram clara divisão sexual do trabalho na alocação do tempo, com a maior parte do trabalho reprodutivo (serviço doméstico e cuidado de crianças) a cargo das mulheres. A ocupação no mercado de trabalho afetava o exercício de atividades domésticas, mas mesmo os homens desocupados assumiam carga de trabalho doméstico menor que as mulheres ocupadas.

Após ajustar os dados de Belo Horizonte por sexo e idade para compará-los à estrutura demográfica do município do Rio de Janeiro, Aguiar identificou uma ampliação nas jornadas de trabalho pago e uma redução da jornada de trabalho não pago de homens e mulheres entre as duas pesquisas. Ainda assim, o trabalho doméstico permanecia sendo uma atividade feminina e as desigualdades permaneciam expressivas, tendo-se observado até mesmo um aumento na contribuição feminina ao trabalho reprodutivo realizado pelo conjunto da população analisada. Aguiar atribui a redução nas jornadas em trabalho não pago mais a um processo de transição demográfica, marcado pela redução no tamanho das famílias e do número de filhos, que restringem o tempo gasto em cuidados e afazeres domésticos, do que a um processo de "redemocratização da divisão dos papéis de gênero no âmbito doméstico" (Aguiar, 2011).

Foi apenas em 2001 que o Instituto Brasileiro de Geografia e Estatística (IBGE) incorporou uma pergunta relacionada ao tempo médio dedicado semanalmente à realização dos afazeres domésticos na Pnad. Os estudos produzidos a partir da Pnad têm-se concentrado em descrições, utilizando-se, para tanto, de médias ou outras medidas de tendência central. Estes estudos mostram que existem diferenças importantes na incidência e na intensidade da realização de trabalho doméstico quando se comparam homens e mulheres de mesma idade no país. Mostram também que o tempo em trabalho reprodutivo vem caindo ao longo dos anos, de forma mais 
intensa para as mulheres do que para os homens (Bruschini, 2006; Fontoura et alii, 2010; Ipea, 2012; 2015).

As análises desenvolvidas com base nas Pnads parecem apontar para fatores como tempo disponível, renda e variáveis relacionadas aos ciclos de vida - como a existência de filhos na família, o número e idade destes filhos, estado civil, idade das pessoas, em particular das mulheres - que ganham importância na determinação da alocação de tempo (Bruschini, 2006; Ipea, 2012; Ramos, 2011). No entanto, também parecem apontar na direção de uma importância mais expressiva da perspectiva de gênero como determinante da alocação de tempo em trabalho doméstico não remunerado e suas desigualdades. Isso porque:

i. ao se compararem homens e mulheres segundo sua participação no mercado de trabalho, a condição de ocupação aparece como característica relevante na determinação do tempo dedicado aos afazeres domésticos - mulheres e homens desocupados gastam mais tempo do que os ocupados. No entanto, as mulheres ocupadas ainda despendem quase 10 horas semanais a mais que os homens desocupados, evidenciando a incapacidade da perspectiva de disponibilidade de tempo em explicar sozinha estas decisões;

ii. a análise da renda do trabalho também aponta na mesma direção, sendo uma característica que também parece fazer bastante sentido para explicar o tempo para afazeres domésticos, porém insuficiente para explicar as desigualdades: o tempo em trabalho não pago diminui à medida que se amplia o rendimento, tanto para homens como para mulheres. De fato, as mulheres que recebem oito salários mínimos ou mais gastam cerca de metade do tempo daquelas que ganham até um salário mínimo. No entanto, elas ainda trabalham mais em casa do que os homens com baixa renda, o que é o oposto do esperado pela teoria dos recursos relativos. Paralelamente, as mulheres em domicílios pobres dedicam-se mais aos afazeres domésticos do que aquelas em domicílios ricos, porém, as mulheres não pobres despendem o dobro de tempo que os homens em domicílios pobres (24 horas semanais contra 12), contrariando os pressupostos da teoria dos recursos relativos ou da barganha (Bruschini, 2006; Ipea, 2012; Ramos, 2011).

O fato de a Pnad contar com apenas uma pergunta sobre trabalho não pago, que procura captar, de forma agregada, muitas tarefas distintas, oferece menos possibilidades analíticas e menos precisão nos dados declarados, uma vez que os entre- 
vistados devem informar sobre atividades que, muitas vezes, são rotineiras e cuja mensuração temporal a posteriori torna-se muito difícil (Aguiar, 2010; Ipea, 2012; Ramos, 2011). Ademais, podem considerar na expressão "afazeres domésticos" um conjunto distinto de variáveis. Entre 2009 e 2010, ao buscar um avanço na coleta destas informações, o IBGE levou a campo uma pesquisa-piloto sobre uso do tempo, aplicada, de modo inédito, no modelo de diário nos estados do Pará, Pernambuco, São Paulo, Rio Grande do Sul e Distrito Federal. Neste caso, por ser coleta do tipo diário, os dados se referem a jornadas diárias em trabalho não pago, diferentemente da Pnad tradicional, que coleta, em quesitos fechados, a jornada semanal.

Os resultados para o conjunto de das unidades da Federação pesquisadas no teste indicam que as maiores diferenças entre homens e mulheres, em termos de tempo gasto em determinadas atividades, estão em trabalho e trabalho voluntário (categoria agregada pelo próprio (BGE), afazeres domésticos e cuidados de pessoas da família. Em 2009, mulheres gastavam cerca de duas horas e vinte minutos a mais por dia que os homens em afazeres domésticos (uma hora e 14 minutos para eles e três horas e 35 minutos para elas) e 27 minutos a mais em cuidados de pessoas da família (12 e 39 minutos, respectivamente). Já em trabalho e trabalho voluntário, os homens despendiam quase duas horas e 30 minutos a mais que as mulheres (cinco horas e 12 minutos contra duas horas e 45 minutos). Para as demais atividades pesquisadas, as distâncias eram menos expressivas, com mulheres tendo jornadas ligeiramente superiores às masculinas em estudos e cuidados pessoais, enquanto os homens estavam pouco à frente em socialização, atividades culturais, hobbies e esportes, uso de meios de comunicação de massa e sono (IBGE, 2012).

\section{Metodologia}

Os dados utilizados neste estudo são oriundos da Pnad, do IBGE, e referem-se ao ano de 2013, último ano para o qual se tem informações disponíveis. Todas as informações apresentadas, portanto, referem-se a jornadas semanais de trabalho pago, não pago e total. Para verificar a robustez das conclusões, replicamos também o estudo com os dados da Pnad 2012 e encontramos resultados muito semelhantes. Ainda que a Pnad não seja uma pesquisa sobre uso do tempo da população brasileira, algumas informações importantes podem ser retiradas de seu questionário, em especial aquelas que se referem à realização e à jornada semanal de trabalho na ocupação principal, secundária, ou em outras ocupações, bem como em afazeres domésticos. As informações de jornada de trabalho, neste contexto, são captadas em quesitos fechados, para os quais os entrevistados devem reportar, em média, as horas despendidas semanalmente em cada uma das atividades. 
Essas informações são coletadas, na Pnad, para a população com idade igual ou superior a dez anos. Para os propósitos deste estudo, porém, foram consideradas apenas as pessoas com idade a partir de 18 anos, uma vez que para a população com idade inferior há uma sobrerrepresentação daqueles que não realizam qualquer tipo de trabalho pago, muito provavelmente devido à dedicação aos estudos. Em 2013, 73,5\% da população de 16 e 17 anos, por exemplo, não realizava trabalho pago, valor que cai para 51\% quando se consideram os jovens de 18 e 19 anos. Ao se realizar esta restrição, cerca de 102 mil observações (equivalentes a pessoas de 0 a 17 anos, inclusive) foram retiradas da base, o que corresponde a $28 \%$ do conjunto de entrevistados pela Pnad.

Para a construção dos indicadores aqui apresentados, trabalhamos com três tipos de tempo: trabalho pago, que corresponde à soma dos tempos de trabalho em todas as ocupações no mercado de trabalho reportadas pelos informantes (principal, secundário e outros); trabalho não pago, que corresponde, nos termos da Pnad, ao tempo gasto em afazeres domésticos; e trabalho total, que é a soma dos tempos em trabalho pago e não pago. Importante destacar que, para a Pnad, afazeres domésticos equivalem às atividades realizadas no âmbito do próprio domicílio, que não se enquadram no conceito de trabalho adotado pela pesquisa e englobam os seguintes itens:

\begin{abstract}
(a) arrumar ou limpar toda ou parte da moradia; (b) cozinhar ou preparar alimentos, passar roupa, lavar roupa ou louça, utilizando, ou não, aparelhos eletrodomésticos para executar estas tarefas para si ou para outro(s) morador(es); (c) orientar ou dirigir trabalhadores domésticos na execução das tarefas domesticas; $(d)$ cuidar de filhos ou menores moradores; ou (e) limpar o quintal ou terreno que circunda a residência.
\end{abstract}

Tanto a jornada em trabalho pago como aquela em trabalho não pago são captadas com dois algarismos em horas inteiras, ou seja, frações de hora são arredondadas para mais quando se trata de 30 minutos ou mais, ou para menos, na situação inversa.

Para além das jornadas em trabalho pago e não pago, cada indivíduo despende seu tempo em uma série de outras atividades, como cuidados pessoais, sono, lazer ou ócio. Ainda que se possa pensar em uma jornada máxima (ou razoável) para o trabalho pago, o mesmo não se dá para as demais atividades, não sendo trivial estabelecer uma duração desejável para cada um destes grupos. Estudos desenvolvidos em outros países, porém, podem oferecer algumas balizas para esta definição. Em relação ao tempo de sono, a literatura aponta que, na média, um adulto deveria 
dormir oito horas a cada dia; já em relação ao tempo em cuidados pessoais, a média varia entre uma e duas horas diárias (Heslop, Smith, Metcalfe, Macleod \& Hart, 2002; NSOT, 2001; Ting \& Malhotra, 2005; USBLS, 2013). No entanto, para lidar com as jornadas mais excessivas de trabalho, pode-se considerar que o tempo mínimo necessário para que um indivíduo se mantenha saudável e ativo seria de oito horas para a dupla sono e cuidados pessoais (Medeiros, Osório \& Costa, 2007).

Como um dia possui 24 horas, uma semana completa dá um total de 168 horas para serem distribuídas nas mais diversas atividades. Ao considerar que as pessoas deveriam despender, pelo menos, oito horas por dia dormindo e com cuidando pessoais (e não realizando qualquer outra atividade adicional), tem-se que, em uma semana completa, sobrariam 112 horas para serem gastas em trabalho (de qualquer natureza), ou 16 horas/dia. Qualquer valor maior do que esse, portanto, foi considerado improvável de ser verificado na prática. Assim, foram eliminados da base todos os registros para os quais se encontrou jornada total de trabalho maior que 112 horas por semana, o que correspondeu a 473 observações, ou $0,2 \%$ do total de casos. 0 objetivo deste procedimento é reduzir distorções causadas por aquilo que provavelmente é um erro de mensuração.

A desigualdade de gênero nas jornadas de trabalho é decomposta seguindo duas metodologias diferentes. Primeiro, realiza-se uma decomposição de médias entre grupos. Uma média de grupos resulta da combinação da média de cada grupo e da proporção de cada grupo no total. Assim, o tempo médio de trabalho total, bem como o de mulheres ou homens, é tratado como o produto da incidência (proporção de pessoas trabalhando) e da duração média das jornadas de trabalho. Isto permite distinguir os efeitos diferenciados da realização de atividades - como, por exemplo, a ocupação no trabalho pago - e a duração dessas atividades de acordo com o gênero. Segundo, aplica-se uma decomposição de fatores do coeficiente de Gini (Rao, 1969), a qual consiste em tratar a desigualdade total de tempo de trabalho (coeficiente de Gini) como o produto do coeficiente de concentração de cada tipo de trabalho exemplo: pago e não pago - pelo tempo total trabalhado em cada tipo de trabalho.

\section{Resultados}

\section{Divisão sexual do trabalho}

Nesta seção apresentamos resultados que indicam que há uma divisão sexual do trabalho e que essa divisão não consiste em simples espelhamento das jornadas de trabalho pago e não pago de homens e mulheres e sim de uma composição específica de incidência (proporção de pessoas que realizam cada tipo de trabalho) e 
duração dos tipos de trabalho que resulta em maior carga total de trabalho para as mulheres. Nosso foco não é na constatação do fato - posto que é um tanto óbvio - e sim sua mensuração mais precisa, em especial no que diz respeito às desigualdades entre as mulheres e entre os homens (ou seja, dentro dos grupos) e a diferença geral entre mulheres e homens (entre os grupos).

A Tabela 1 mostra os tempos médios de trabalho pago e não pago (doméstico) de homens e mulheres no Brasil, em 2013. Mostra também a incidência desses tipos de trabalho, isto é, a proporção de pessoas que os realiza. Além disso, decompõe o tempo médio trabalhado entre efeitos de incidência e duração. Esse tempo é resultado do produto da proporção de pessoas que realiza cada atividade e a duração média dessa atividade entre as pessoas que a realizam. Nela é possível observar que a população adulta, como um todo, empreende mais tempo no trabalho pago do que no trabalho não pago (25,7 e 14 horas, respectivamente). Isso resulta de maior duração das jornadas de trabalho pago e não de sua incidência mais frequente. $\mathrm{Na}$ verdade, o trabalho não pago é realizado por um número levemente maior de pessoas, mas por períodos substancialmente mais breves.

TABELA 1

DECOMPOSIÇÃO DOS TEMPOS MÉDIOS DE TRABALHO

ENTRE EFEITOS DE INCIDÊNCIA E DURAÇÃO, SEGUNDO O SEXO (BRASIL, 2013)

\begin{tabular}{|c|c|c|c|c|c|c|c|c|c|}
\hline \multirow{2}{*}{ Sexo } & \multirow{2}{*}{ Média trabalho total } & & \multicolumn{3}{|c|}{ Doméstico } & + & \multicolumn{3}{|c|}{ Pago } \\
\hline & & & Incidência $\left(\rho_{1}\right)$ & * & Duração $\left(\mu_{\uparrow}\right)$ & + & Incidência $\left(\rho_{1}\right)$ & $*$ & Duração $\left(\mu_{1}\right)$ \\
\hline \multirow{2}{*}{ Masculino } & \multirow{2}{*}{37,88} & \multirow{2}{*}{$=$} & 0,460 & $*$ & 10,73 & + & 0,770 & $*$ & 42,78 \\
\hline & & & \multicolumn{3}{|c|}{4,94} & + & \multicolumn{3}{|c|}{32,94} \\
\hline \multirow{2}{*}{ Feminino } & \multirow{2}{*}{41,21} & \multirow{2}{*}{$=$} & 0,879 & $*$ & 25,21 & + & 0,522 & $*$ & 36,49 \\
\hline & & & \multicolumn{3}{|c|}{22,16} & + & \multicolumn{3}{|c|}{19,05} \\
\hline \multirow{2}{*}{ Total } & \multirow{2}{*}{39,61} & \multirow{2}{*}{$=$} & 0,679 & $*$ & 20,54 & + & 0,640 & $*$ & 40,09 \\
\hline & & & \multicolumn{3}{|c|}{13,95} & + & \multicolumn{3}{|c|}{25,66} \\
\hline
\end{tabular}

O tempo empregado no trabalho pago dos homens é superior ao empregado pelas mulheres. Há uma maior proporção de homens trabalhando e suas jornadas são, em média, maiores que as das mulheres. No trabalho não pago, porém, ocorre o inverso, com mais mulheres trabalhando, e estas trabalhando por mais horas por semana. A combinação dos dois tipos de trabalho faz com que o tempo médio de trabalho total das mulheres seja superior ao dos homens. Em outras palavras, há um certo grau de divisão sexual dos tipos de trabalho realizados e nessa divisão muitos homens e mulheres acumulam duas jornadas, mas esse acúmulo é desproporcional e o resultado disso é que o tempo total de trabalho das mulheres é, em média, superior ao dos homens (41 horas para elas e 37,8, para eles). 
As mulheres realizam $54,4 \%$ do total de horas despendidas semanalmente em todos os trabalhos. A participação feminina, porém, é significativamente mais intensa no trabalho não pago ( $83 \%$ das horas trabalhadas são produto do trabalho das mulheres) e menos significativa no trabalho pago, para o qual os homens respondem por quase dois terços $(61,2 \%)$ do total.

As diferenças entre médias de homens e mulheres são óbvias e correspondem ao que já havia sido identificado pela literatura sobre o assunto em vários países, incluindo o Brasil. Interessa, porém, identificar mais claramente o que determina essas diferenças de médias e suas implicações para as desigualdades de gênero. Para isso, na Tabela 2 simulamos o que ocorreria com a duração média das jornadas de trabalho de homens e mulheres caso os fatores fossem intercambiados, ou seja, calculamos qual seria a duração média do trabalho não pago dos homens caso a proporção de homens realizando tarefas domésticas fosse a mesma das mulheres, ou caso a duração do tempo empregado fosse aquela observada, em média, entre as mulheres. Repetimos a mesma simulação para trabalho pago e para mulheres, e calculamos as diferenças (desvios) entre as situações observada e simulada de homens e mulheres.

TABELA 2

DURAÇÃO MÉdIA SIMULADA DAS JORNADAS DE TRABALHO (BRASIL, 2013)

\begin{tabular}{|c|c|c|c|c|c|c|c|}
\multirow{2}{*}{ Trabalho } & $\begin{array}{c}\text { Fatores trocados } \\
\text { (masculino/ feminino) }\end{array}$ & \multicolumn{2}{|c|}{ Jornadas simuladas } & \multicolumn{2}{|c|}{$\begin{array}{c}\text { Desvio das médias } \\
\text { observadas }\end{array}$} & \multicolumn{2}{|c|}{$\begin{array}{c}\text { Desvio das médias } \\
\text { observadas }\end{array}$} \\
\cline { 3 - 8 } & Masculino & Feminino & Masculino & Feminino & Masculino & Feminino \\
\hline \multirow{2}{*}{ Não pago } & Incidência $\left(\rho_{1}\right)$ & 41,4 & 30,7 & 3,5 & $-10,6$ & $109,2 \%$ & $74,4 \%$ \\
\cline { 2 - 8 } & Duração $\left(\mu_{1}\right)$ & 44,6 & 28,5 & 6,7 & $-12,7$ & $117,6 \%$ & $69,1 \%$ \\
\hline \multirow{2}{*}{ Pago } & Incidência $\left(\rho_{1}\right)$ & 27,3 & 50,3 & $-10,6$ & 9,1 & $72,0 \%$ & $122,0 \%$ \\
\cline { 2 - 8 } & Duração $\left(\mu_{1}\right)$ & 33,0 & 44,5 & $-4,8$ & 3,3 & $87,2 \%$ & $108,0 \%$ \\
\hline
\end{tabular}

Fonte: IBGE, Pnad 2013, microdados.

Para colocar de modo sintético, o diferencial de gênero na duração das jornadas de trabalho é mais fortemente marcado pela proporção de pessoas que fazem trabalho pago e pela duração do trabalho não pago. Isso porque muitos homens realizam trabalho não pago, mas de curta duração, e as mulheres que realizam trabalho pago o fazem com jornadas muito próximas às dos homens. A composição das jornadas, portanto, não resulta de uma mera divisão de tarefas, com a carga total de trabalho de homens e mulheres sendo, na média, bem mais afetada pela carga de trabalho doméstico. Se a proporção de mulheres realizando trabalho não pago fosse a mesma dos homens, a jornada feminina de trabalho seria quase um quarto menor do que a observada. Se a duração do trabalho doméstico feminino fosse a mesma dos homens, a queda seria ainda mais acentuada: as mulheres trabalhariam quase um 
terço menos do que de fato trabalham. Por outro lado, no que diz respeito a trabaIho pago, se a incidência masculina fosse aplicada às mulheres, haveria um aumento de quase um quarto em seu tempo trabalhado, mas a simulação de equivalência de duração produziria um aumento de magnitude muito menor.

As diferenças na divisão sexual do trabalho se expressam muito além das médias. Quando a desigualdade é analisada em detalhe, nota-se mais claramente que as distribuições de trabalho pago e não pago de homens e mulheres não são simplesmente espelhadas, como se costuma acreditar, e sim diferentes em termos de incidência e duração das jornadas. É justamente por trás dessa combinação que se encontra o acúmulo maior de jornada de trabalho entre as mulheres. Um mero espelhamento resultaria tão somente em uma divisão de tarefas (e não em um acúmulo desigual de jornadas), e não é isso o que ocorre.

O Gráfico 1 apresenta as curvas de quantis ou paradas de Pen dos tempos de trabaIho pago e não pago no Brasil, segundo o sexo. No eixo horizontal são representadas as frações de população - de 0\% a 100\% - e no eixo vertical o tempo trabalhado, em horas semanais. As curvas, portanto, são sensíveis a desigualdades absolutas, isto é, diferenças na duração das jornadas. Retas estão associadas à igualdade ao passo que quanto maior a inclinação, maior a desigualdade entre um ponto e outro das curvas.

GRÁFICO 1

DistribuIÇÃO DOS TEMPOS DE TRABALHO PAGO E NÃO PAGO, SEGUNDO O SEXO (BRASIL, 2013)

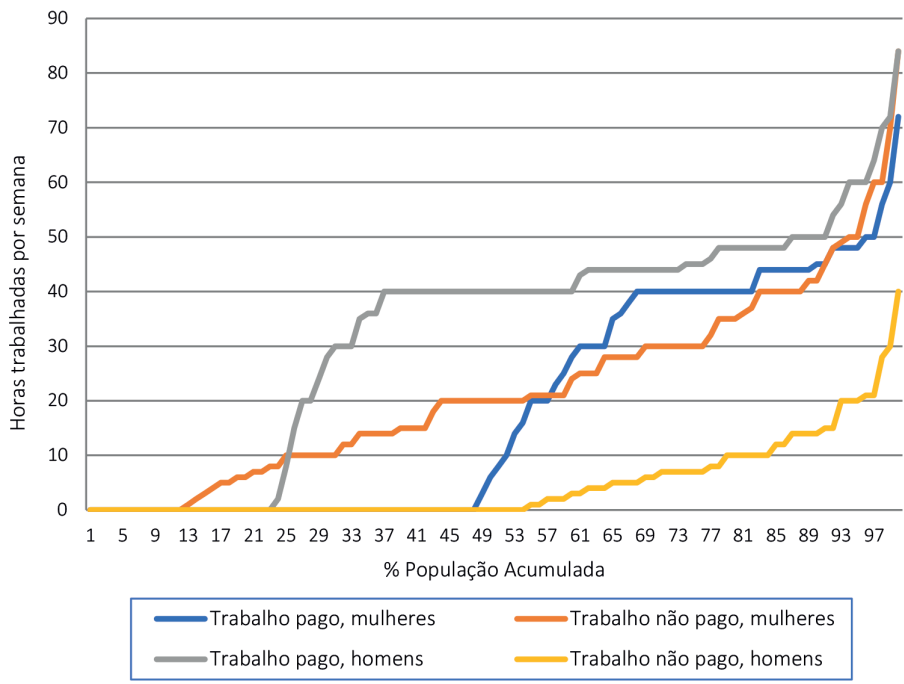

Fonte: IBGE, Pnad 2013, microdados. 
Uma análise das curvas limitada à incidência dos tipos de trabalho parece reforçar a hipótese de espelhamento. Praticamente toda a população feminina adulta (88\%) realiza atividades de trabalho não pago. No entanto, apenas pouco menos de metade dos homens (46\%) emprega tempo em trabalho não pago. O inverso ocorre com o trabalho pago: é realizado por pouco mais da metade (52\%) das mulheres e pela grande maioria (77\%) dos homens.

No entanto, essa hipótese é afastada quando se consideram as diferenças na duração das atividades. A duração da jornada de trabalho pago é pouco diferenciada entre homens e mulheres e, em ambas populações, é homogênea ao longo de boa parte da distribuição. Isso pode ser percebido pelo Gráfico 1, uma vez que as curvas de trabalho pago têm basicamente o mesmo formato, diferenciando-se em relação ao ponto no qual saem da jornada zero, mas aproximando-se conforme se avança na distribuição. A diferença entre homens e mulheres no trabalho pago, portanto, deve-se muito mais à incidência do que à duração deste trabalho. Como se verá adiante, essa polarização entre trabalhar ou não é o principal fator associado às desigualdades entre mulheres ou homens (dentro dos grupos).

No trabalho não pago, por outro lado, as diferenças de duração são muito maiores. Embora grande parcela da população masculina empregue tempo em trabalho não pago, este tempo é invariavelmente pequeno e jamais se aproxima do tempo empregado em atividades pagas, seja de homens ou mulheres. Entre as mulheres, as durações de jornada de trabalho não pago são bem maiores e para um quinto das mulheres o tempo de trabalho doméstico se aproxima ou mesmo ultrapassa o que seria uma jornada integral de trabalho pago de 40 horas semanais.

\section{Desigualdades entre e dentro dos grupos}

As inclinações das curvas no Gráfico 1, incluindo aquelas causadas por mudanças abruptas nas distribuições, mostram que nem homens, nem mulheres constituem grupos homogêneos. Essas heterogeneidades internas podem fazer com que um pequeno grupo de pessoas afete substantivamente os totais ou mesmo as médias de homens e mulheres. Há, portanto, diferenças dentro de cada grupo que merecem ser analisadas em mais detalhe e comparadas entre si. Para isso construímos, para cada tipo de trabalho, curvas de Lorenz, que permitem visualizar o quanto do trabalho total é realizado por cada parcela da população de cada sexo, possibilitando-nos uma análise da desigualdade na distribuição de tempo, semelhante à que se realiza para a distribuição de renda da população. 
A alocação de tempo para o trabalho total (pago e não pago) não é uniforme na sociedade. Ao contrário, existe uma razoável concentração, principalmente quando se considera que há um limite máximo de horas para o trabalho ao longo de uma semana. As curvas do Gráfico 2 mostram, por exemplo, que metade de todo o tempo de trabalho de adultos no Brasil é empreendido por cerca de $30 \%$ da população que mais trabaIha. Os $30 \%$ que menos trabalham, por sua vez, acumulam em torno de um décimo de todo o tempo de trabalho. A razão entre os extremos 30\%/30\%, portanto, situa-se em torno de uma concentração de uma para cada cinco horas em cada ponta da distribuição. Essa concentração se observa tanto entre homens como entre mulheres. As curvas de Lorenz das distribuições de tempo de trabalho total de ambos os sexos são muito semelhantes e, como elas se cruzam, não é possível dizer, inequivocamente, qual distribuição é mais desigual. As diferenças entre sexos tornam-se evidentes apenas quando os tipos de trabalho são desagregados, como se verá a seguir.

\section{GRÁFICO 2}

CURVA DE LORENZ DO TEMPO DE TRABALHO TOTAL, SEGUNDO O SEXO (BRASIL, 2013)

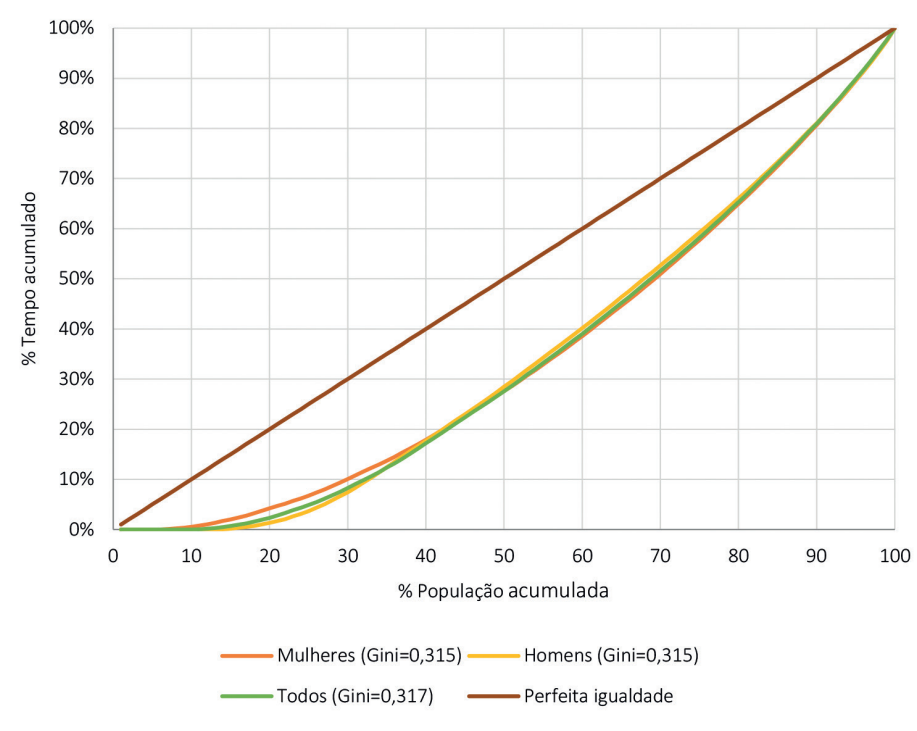

Fonte: IBGE, Pnad 2013, microdados.

O Gráfico 3 apresenta a curva de Lorenz do tempo de trabalho pago. Com a especificação do tipo de trabalho, as diferenças entre homens e mulheres ficam evidentes. A desigualdade em tempo trabalhado das mulheres é muito superior à dos homens, como se nota pelo arco maior da curva das mulheres. Há, porém, uma característica das curvas de Lorenz de tempo de trabalho pago que deve ser notada. A inclinação das curvas é bastante estável até um ponto, muda rapidamente e 
se estabiliza novamente após o ponto de mudança, fazendo com que as curvas de Lorenz pareçam o resultado da combinação de duas retas. Esse tipo de comportamento das curvas geralmente está associado a uma polarização na distribuição. Isso indica que a maior parte da desigualdade, tanto para homens como para muIheres, resulta do fato de as pessoas trabalharem ou não. Uma vez trabalhando, a duração das jornadas de trabalho tende a ser uniforme. O que faz as mulheres serem mais desiguais entre si, quando comparadas aos homens, não é a duração de suas jornadas de trabalho pago - que poderia flutuar em decorrência de trabaIho em tempo parcial, por exemplo - e sim o ponto em que a polarização ocorre. É a participação no mercado de trabalho, e não a duração das jornadas, o que mais diferencia umas mulheres das outras (o mesmo ocorre para os homens) e as diferenças nas proporções de pessoas que trabalham (e não a duração das jornadas) o que distingue homens de mulheres.

\section{GRÁFICO 3}

CURVA DE LORENZ DO TEMPO DE TRABALHO PAGO, S EGUNDO O SEXO (BRASIL, 2013)

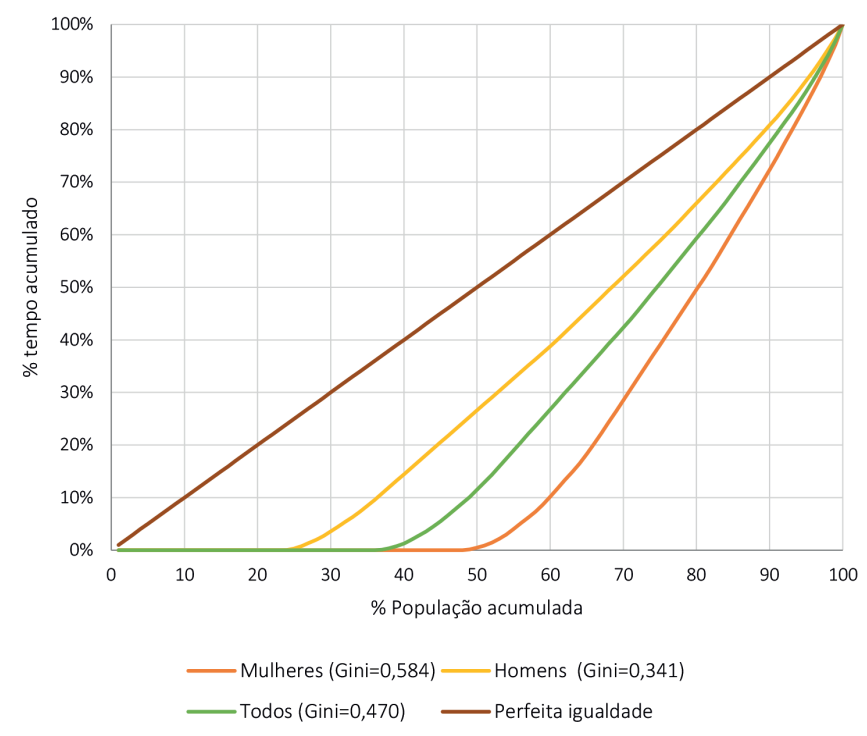

Fonte: IBGE, Pnad 2013, microdados.

A desigualdade na distribuição do tempo de trabalho não pago é completamente diferente. Aqui, a polarização só é aparente no caso dos homens e, ainda assim, menos nítida. No caso das mulheres, há uma concentração progressiva, tal como se pode observar no Gráfico 4. Realizar ou não trabalho doméstico é um componente importante da desigualdade entre os homens, com relevância muito menor entre as mulheres. 
Se na distribuição do tempo de trabalho pago a desigualdade era maior entre as mulheres, no trabalho não pago a situação se inverte. Homens são muito mais heterogêneos no que diz respeito ao tempo que empregam no trabalho doméstico. Metade de todo o trabalho doméstico masculino é realizado por apenas $10 \%$ dos homens. As mulheres são um grupo muito mais uniforme e, embora exista alguma desigualdade entre elas, essa desigualdade é significativamente mais baixa e até mesmo menor que aquela observada na distribuição do tempo de trabalho pago.

GRÁFICO 4

CuRVA de LORENZ DO TEMPO DE TRABALHO NÃO PAGO, SEGUNDO O SEXO (BRASIL, 2013)

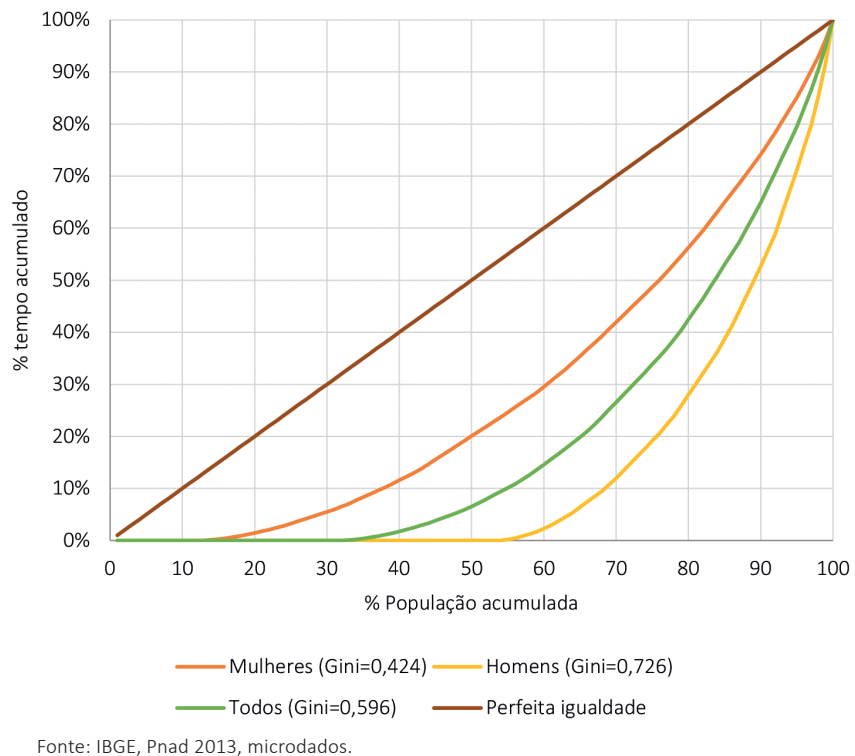

\section{Acúmulo de jornada}

Homens e mulheres acumulam duas jornadas de trabalho, mas esse acúmulo não é uniforme: primeiro, porque apenas parte da população acumula duas jornadas; segundo, porque a duração das jornadas acumuladas varia entre e dentro dos grupos; terceiro, porque a concentração de cada tipo de trabalho varia segundo o sexo. 0 acúmulo de jornadas afeta tanto a forma (desigualdade) quanto o nível da distribuição. Para analisar os efeitos do acúmulo sobre a forma da distribuição, utilizamos curvas de concentração e decomposições do coeficiente de Gini. Para os efeitos sobre o nível, utilizaremos curvas de Lorenz generalizadas.

Começamos combinando informações do Gráfico 1, anteriormente apresentado, com as do Gráfico 5, abaixo, que apresenta as curvas de concentração dos tempos 
de trabalho, segundo o sexo. Nelas a população total encontra-se ordenada segundo o tempo de trabalho total e cada curva representa o quanto cada tipo de trabaIho está concentrado em diferentes pontos da distribuição de trabalho total. Indica, por exemplo, quanto do tempo de trabalho pago feminino está concentrado entre as pessoas que trabalham mais na população.

GRÁFICO 5

CURVAS DE CONCENTRAÇÃO DOS TEMPOS DE TRABALHO, SEGUNDO O SEXO (BRASIL, 2013)

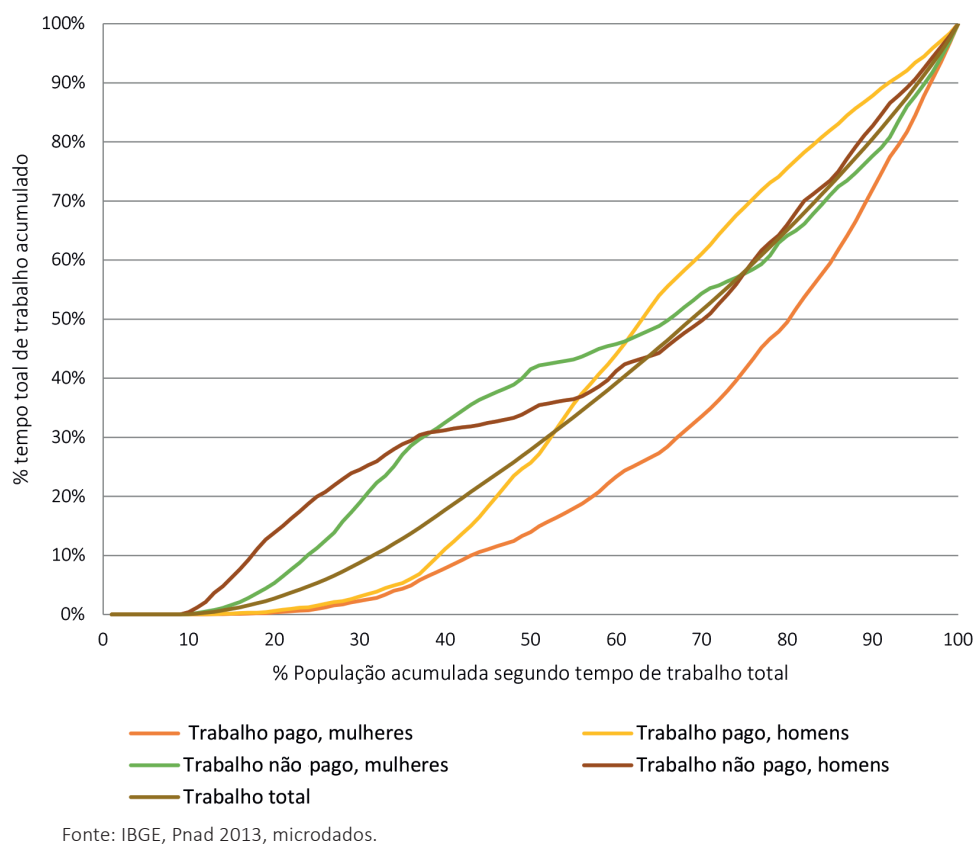

O Gráfico 1 indica que apenas cerca de metade dos homens e das mulheres do Brasil acumulam duas jornadas de trabalho. Isso ocorre, por um lado, porque apenas parte das mulheres realiza trabalho pago e, por outro, porque parte dos homens não emprega qualquer tempo em trabalho doméstico. Obviamente, a outra metade tem duas jornadas de trabalho, mas como é fácil inferir pelo Gráfico 1 e pelos resultados da Tabela 1, a duração da dupla jornada acumulada tende a ser, na média, maior para as mulheres. Com as curvas de concentração do Gráfico 5 é possível começar a analisar a composição não apenas das médias, mas de toda a distribuição.

Em termos gerais, as mulheres respondem por um dos extremos da concentração. Ao considerar que as mulheres respondem por uma parte grande do tempo de trabalho total da sociedade, é de se esperar que a maior parte da desigualdade total 
no uso do tempo na sociedade brasileira esteja associada à desigualdade de carga de trabalho feminina. O tempo de trabalho pago feminino é o mais concentrado de todos e isso decorre da grande polarização que existe entre as mulheres que estão ou não empregadas no mercado de trabalho. O tempo de trabalho não pago, por outro lado, é um dos menos concentrados e, neste caso, o motivo é a ausência de polarização, mais do que a igualdade no trabalho doméstico.

Estritamente falando, não é possível julgar inequivocamente o grau de concentração dos demais tempos de trabalho. Isso porque duas curvas de concentração têm formatos peculiares e se cruzam. Há, por exemplo, trechos da distribuição em que o trabalho não pago dos homens é o menos concentrado de todos os tempos, bem como uns poucos outros trechos em que responde pelo maior nível de concentração.

A análise da contribuição de cada tempo de trabalho para a desigualdade total no uso do tempo no Brasil requer a decomposição de uma medida sintética de desigualdade. Com essa finalidade, a Tabela 3 apresenta a decomposição do coeficiente de Gini da distribuição de tempo total de trabalho em função dos tipos de trabalho realizados por pessoas de cada sexo. O coeficiente de Gini - que é um caso particular de coeficiente de concentração - resulta da soma das concentrações de cada tipo de trabalho, multiplicada pela parcela desse tipo de trabalho no tempo total trabalhado (Rao, 1969). Para facilitar a interpretação, acrescentamos na Tabela 3 uma coluna com a contribuição de cada tipo de trabalho para a desigualdade expressa como porcentagem do coeficiente de Gini.

TABELA 3

DECOMPOSIÇÃO DA DESIGUALDADE TOTAL

EM FUNÇÃO DOS TIPOS DE TRABALHO (BRASIL 2013)

\begin{tabular}{|c|c|c|c|}
\hline Fatores & $\begin{array}{c}\text { Coeficiente de } \\
\text { concentração }\end{array}$ & \% do tempo total & \% do Gini* \\
\hline Tempo de trabalho pago dos homens & 0,282508 & 39,6 & 35,3 \\
\hline Tempo de trabalho não pago dos homens & 0,215499 & 5,9 & 4,0 \\
\hline Tempo de trabalho pago das mulheres & 0,500682 & 25,2 & 39,7 \\
\hline Tempo de trabalho não pago das mulheres & 0,226989 & 29,3 & 21,0 \\
\hline
\end{tabular}

* Índice de Gini do Trabalho Total da População Total = 0,3171.

Fonte: IBGE, Pnad 2013, microdados.

O trabalho pago dos homens responde pelo mais proeminente dos fatores que compõem o uso do tempo em trabalho da sociedade. Seu trabalho não pago, por outro lado, é o menos importante de todos. Isso faz com que, uma vez acumuladas as jornadas, as mulheres respondam pela maior parte de todo o trabalho realizado no país. Ao contrário dos homens, os tempos totais de trabalho feminino pago e não pago são bem próximos, com pequena preponderância do trabalho doméstico. 
O coeficiente de Gini da distribuição de tempo de trabalho total é 0,3171, o que revela uma desigualdade elevada, quando se considera que a duração de uma semana, em horas, é bastante limitada. Os tempos menos concentrados são os de trabalho não pago. Entre os homens a concentração é baixa por uma combinação de duas características peculiares: a maioria não faz trabalho doméstico e, quando faz, trabalha pouco; uma parte pequena, mas não irrelevante, dos homens que fazem trabalho doméstico, são homens sem trabalho pago. Entre as mulheres, a menor concentração do trabalho não pago ocorre porque quase a metade delas não acumula duas jornadas de trabalho.

A principal contribuição para a desigualdade total vem dos trabalhos femininos. Pouco mais de $60 \%$ do coeficiente de Gini estão relacionados a eles. O peso maior vem do trabalho feminino pago, que não só é bastante concentrado, como responde por um quarto de todo o tempo de trabalho da sociedade. A combinação de alta concentração com elevada proporção resulta em contribuição de 39,7\% para a desigualdade total. Como já notado anteriormente, a polarização entre estar ou não ocupada no mercado de trabalho é a principal responsável pela alta concentração. No polo oposto, encontra-se o trabalho não pago masculino que, embora tão concentrado quanto o trabalho não pago feminino, tem duração tão curta que acaba por não ter grande relevância para a desigualdade.

Como a divisão sexual do trabalho não é simplesmente uma estrutura de papéis invertidos e como há desigualdades dentro dos grupos das mulheres e dos homens, a interação entre o nível e a concentração de cada tipo de trabalho resulta em acúmulos diferenciados de jornada. Quando a dupla jornada é considerada, as mulheres trabalham mais que os homens, não apenas nas médias, mas ao longo de toda a distribuição.

Isso não pode ser verificado diretamente nas paradas de Pen (curvas de quantil) do Gráfico 1, pois há cruzamento entre curvas. Pode, no entanto, ser visualizado por meio de curvas de Lorenz generalizadas do tempo total de trabalho, segundo o sexo. Estas são simplesmente curvas de Lorenz em que as proporções acumuladas de tempo são multiplicadas pelas médias. A escala resultante dessa multiplicação não tem significado substantivo e deve ser entendida apenas como medida de carga total. A multiplicação faz com que essas curvas considerem, simultaneamente, a desigualdade e o nível das distribuições de tempo das mulheres e dos homens. Particularmente importantes são os casos de dominância de uma curva sobre a outra, conhecidos como dominância de segunda ordem. Esta ocorre quando uma curva está invariavelmente sobre a outra. Neste estudo, a dominância significa que uma distribuição (como veremos, o tempo das mulheres) tem, invariavelmente, carga de trabalho superior ao de outra. 


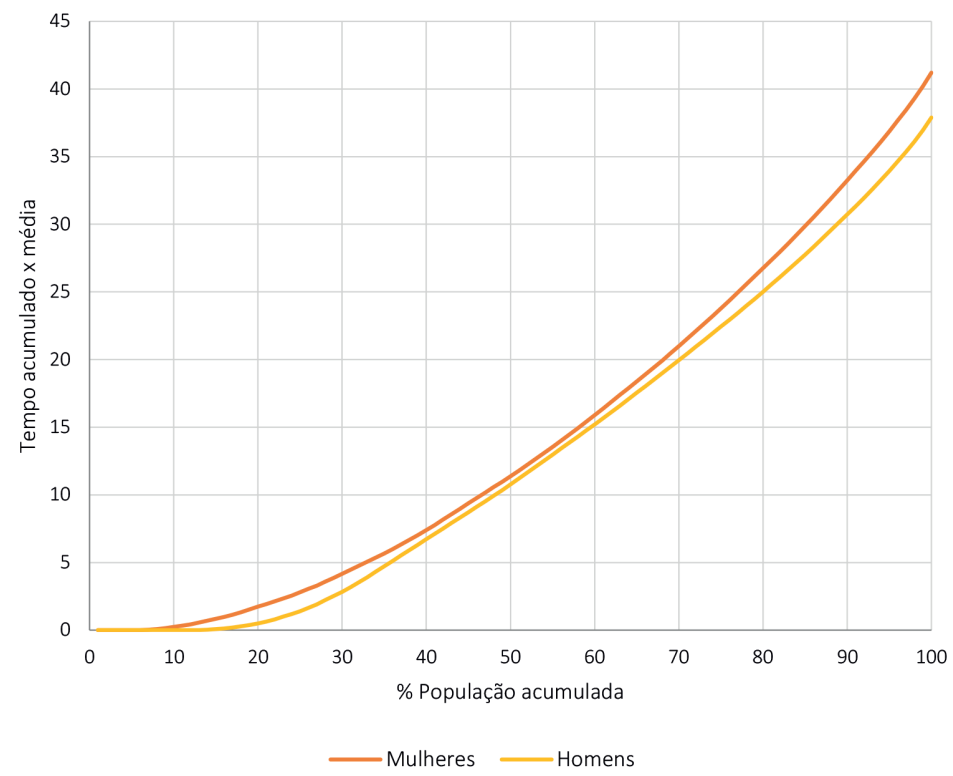

Fonte: IBGE, Pnad 2013, microdados.

O Gráfico 6 indica que as curvas de Lorenz generalizadas do tempo total de trabaIho masculino e feminino são semelhantes e tornam-se bem próximas no centro da distribuição. Logo, apesar das diferenças na composição de seus tempos de trabaIho, mulheres e homens terminam tendo cargas totais de trabalho parecidas. Isso vale tanto para mulheres e homens que trabalham pouco como para quem tem jornadas longas. Para uma parcela de aproximadamente um quinto da população, que vai dos $40 \%$ aos $60 \%$ das pessoas ordenadas segundo seu tempo de trabalho total, as cargas de trabalho são praticamente idênticas. A diferenciação entre sexo torna-se maior apenas nos casos mais extremos, quando as jornadas de trabalho total são bem mais longas, e pode ser visualizada no quinto superior da distribuição $(80 \%$ a $100 \%)$.

Embora as curvas sejam semelhantes, há dominância de ordem entre elas. A curva que representa a distribuição do tempo total trabalhado feminino é sempre superior à curva masculina, tocando-a apenas no nível zero (é um caso de dominância fraca). Portanto, é possível concluir que a carga total de trabalho das mulheres é, invariavelmente, superior à dos homens, seja quando se comparam os homens e as mulheres que trabalham pouco, as pessoas que trabalham muito, ou qualquer outra comparação. Há, evidentemente, alguns homens que trabalham mais do que uma 
parte das mulheres, mas, quando comparados com suas equivalentes, os homens sempre trabalham menos.

\section{Conclusão}

A constatação geral de que a divisão sexual do trabalho no Brasil não se caracteriza simplesmente por um espelhamento das jornadas de trabalho pago e não pago de homens e mulheres, e por isso tem como resultado uma carga total de trabalho maior para as mulheres, encontra respaldo quando mensurada a partir dos dados de pesquisas domiciliares e é corroborada mesmo quando se leva em conta toda a desigualdade existente dentro dos grupos formados por homens e mulheres.

Cerca de metade das mulheres e metade dos homens não acumula duas jornadas de trabalho. Entre os homens, isso ocorre porque a maioria não realiza trabalhos domésticos regulares, entre as mulheres porque grande parte não está ocupada no mercado de trabalho. O acúmulo, quando ocorre, é diferenciado em sua composição. No que se refere a essa composição, os principais determinantes do diferencial de gênero na duração das jornadas de trabalho são a proporção de pessoas que fazem trabalho pago e a duração do trabalho não pago.

Como homens empregam mais tempo em trabalho pago, mas com pequena carga de trabalho não pago, e mulheres têm jornadas semelhantes (levemente inferiores) de trabalho pago, mas muito mais longas de trabalho não pago em relação à dos homens, o acúmulo de jornadas é desproporcional, fazendo com que o tempo total de trabalho das mulheres seja, em média, superior ao dos homens.

Homens e mulheres não constituem grupos homogêneos. Há uma desigualdade relativamente elevada dentro desses grupos. A maior parte dessa desigualdade resulta do fato de as pessoas trabalharem ou não, isto é, decorre de polarização. Tanto para mulheres como para homens, não é a duração das jornadas e sim a ocupação no mercado de trabalho o que mais diferencia umas pessoas das outras, bem como é a diferença nas proporções de pessoas que trabalham o que mais diferencia homens de mulheres.

Quando se decompõe o trabalho total da sociedade segundo o sexo e os tipos de trabalho, o trabalho pago masculino responde pelo componente de maior parcela no total. Seu trabalho não pago, por outro lado, é o componente de menor relevância. Entre as mulheres, há menos diferença, com as cargas totais de trabalho feminino pago e não pago próximas. Quando, para se analisar a desigualdade, se estimam as concentrações do tempo ao longo da distribuição de tempo total empregado na população, 
o tempo de trabalho pago das mulheres é o fator mais concentrado. Os demais tipos de trabalho têm concentração similar. Ao se ponderar os níveis de concentração pelas parcelas no total, o tipo de trabalho que contribui para a maior parte da desigualdade total na sociedade ( $40 \%$ do coeficiente de Gini) é o trabalho pago das mulheres, seguido do trabalho pago dos homens (35\%) e não pago das mulheres (21\%). O trabalho não pago dos homens não contribui de forma relevante (4\%). Em outras palavras, a maior contribuição para a desigualdade total vem dos trabalhos femininos, cuja causa predominante de concentração é a polarização no mercado de trabalho.

Apesar das grandes diferenças na composição de seus tempos de trabalho, homens e mulheres acabam tendo cargas totais de trabalho parecidas. Este é um resultado que se mantém mesmo quando a desigualdade dentro dos grupos é considerada, isto é, quando homens que trabalham menos são comparados com mulheres que trabalham menos, e assim sucessivamente até cargas mais altas de trabalho. Porém, mesmo considerando-se a desigualdade, a carga de trabalho das mulheres é invariavelmente superior à dos homens. Comparadas a seus equivalentes ao longo da distribuição do tempo de trabalho total, as mulheres sempre trabalham mais.

\section{Gender inequalities in the allocation of time in paid and unpaid labor in Brazil, 2013}

Abstract: We examine gender inequalities in time use in Brazil by decomposing the total time employed in work in paid (market) and unpaid work (domestic). Data comes from the 2013 National Household Survey, Pnad. We found large inequalities within the subgroups of men and women. Most inequality within these groups is related to the polarization between working or not. Female work, both paid and unpaid, is what contributes more to total inequality in society. The domestic work among men is less common and, therefore, contributes little to total inequality. The main determinants of the gender differential in working hours are the proportion of people who do some paid work and the duration of unpaid work. The sexual division of labor is not characterized by a mirroring of activities. Therefore, women invariably work more than men, even when within group inequalities are considered.

keywords: time use, housework, household labor, sexual division of labor.

\section{Referências}

AGUIAR, N. Mudanças do uso do tempo na sociedade brasileira. Política \& Trabalho, n. 34, p. 73-106, 2011.

- Metodologias para o levantamento do uso do tempo na vida cotidiana no Brasil. Revista Econômica, v. 12, n. 1, 2010. Disponível em: <//www.revistaeconomica.uff.br/index.php/revistaeconomica/article/viewFile/12/11>. 
- Múltiplas temporalidades de referência: trabalho doméstico e trabalho remunerado: análise dos usos do tempo em Belo Horizonte, Minas Gerais: um projeto piloto para zonas metropolitanas brasileiras. Belo Horizonte: UFMG, 2001.

BAXTER, J. To marry or not to marry marital status and the household division of labor. Journal of Family Issues, v. 26, n. 3, p. 300-321, 2005. Disponível em: <https:// doi.org/10.1177/0192513X04270473>.

BECKER, G. S. A treatise on the family. Camfridge (MA): Harvard University Press, 1991.

BIANCHI, S. M.; MILKIE, M. A.; SAYER, L. C.; ROBINSON, J. P. Is anyone doing the housework? Trends in the gender division of household labor. Social Forces, v. 79, n. 1, p. 191-228, 2000. Disponível em: <https://doi.org/10.1093/sf/79.1.191>.

BRINES, J. Economic dependency, gender, and the division of labor at home. American Journal of Sociology, v. 100, n. 3, p. 652-688, 1994.

BRUSCHINI, C. Trabalho doméstico: inatividade econômica ou trabalho não remunerado. Revista Brasileira de Estudos Populacionais, v. 23, n. 2, p. 331-353, 2006.

COLTRANE, S. Research on household labor: modeling and measuring the social embeddedness of routine family work. Journal of Marriage and Family, v. 62, n. 4, p. 12081233, 2000. Disponível em: <https://doi.org/10.1111/j.1741-3737.2000.01208>.

FONTOURA, N.; ARAÚJO, C. (Eds.). Uso do tempo e gênero. Rio de Janeiro: UERJ, 2016.

FONTOURA, N. et alii. Pesquisas de uso do tempo no Brasil: contribuições para a formulação de políticas de conciliação entre trabalho, família e vida pessoal. Revista Econômica, v. 12, n. 1, 2010.

FUWA, M. Macro-level gender inequality and the division of household labor in 22 countries. American Sociological Review, v. 69, n. 1, p. 751-767, 2004.

GIDDINGS, L. A. Political economy and the construction of gender: the example of housework within same-sex households. Feminist Economics, v. 4, n. 2, p. 97-106, 1998. Disponível em: <https://doi.org/10.1080/135457098338491>.

GREENSTEIN, T. N. Economic dependence, gender, and the division of labor in the home: a replication and extension. Journal of Marriage and Family, v. 62, n. 2, p. 322335 , 2000. Disponível em: <https://doi.org/10.1111/j.1741-3737.2000.00322>. 
HESLOP, P.; SMITH, G. D.; METCALFE, C.; MACLEOD, J.; HART, C. Sleep duration and mortality: the effect of short or long sleep duration on cardiovascular and all-cause mortality in working men and women. Sleep Medicine, v. 3, n. 4, p. 305-314, 2002.

INSTITUTO BRASILEIRO DE GEOGRAFIA E ESTATÍ́STICA (IBGE). Pesquisa piloto de uso do tempo 2009: primeiros resultados. Apresentada no XII Fórum do Sistema Integrado de Pesquisas Domiciliares, Rio de Janeiro, Dez. 2012. Retrieved from http:// www.ibge.gov.br/home/estatistica/indicadores/sipd/decimo_segundo_forum/uso_ tempo_2009.pdf>.

FUNDAÇÃO INSTITUTO DE PESQUISA ECONÔMICA APLICADA (IPEA). Retrato das desigualdades de gênero e raça. Disponível em: <www.ipea.gov.br/retrato>. Acesso em: 10 Jun. 2015.

- Trabalho para o mercado e trabalho para casa: persistentes desigualdades de gênero. Comunicado Ipea, n. 149, 2012.

KURDEK, L. A. (). The allocation of household labor in gay, lesbian, and heterosexual married couples. Journal of Social Issues, v. 49, n. 3, p. 127-139, 1993. Disponível em: <https://doi.org/10.1111/j.1540-4560.1993.tb01172>.

LENNON, M. C.; ROSENFIELD, S. Relative fairness and the division of housework: the importance of options. American Journal of Sociology, p. 506-531, 1994.

MEDEIROS, M.; COSTA, J.; OSORIO, R. Gender inequalities in allocating time to paid and unpaid work: evidence from bolivia. In: ANTONOPOULOS, R.; HIRWAY, I. (Eds.). Unpaid work and the economy: gender, time use and poverty in developing countries, p. 58-75. Basingstoke; New York: Palgrave Macmillan, 2010.

MEDEIROS, M.; OSÓRIO, R. G.; COSTA, J. Gender inequalities in allocating time to paid and unpaid work: evidence from Bolivia. Working Papers, n. 495, 2007. The Levy Economics Institute. Disponível em: <http://www.econstor.eu/handle/ $10419 / 31656>$.

NATALIER, K. "I'm not his wife" doing gender and doing housework in the absence of women. Journal of Sociology, v. 39, n. 3, p. 253-269, 2003, Disponível em: <https://doi.org/10.1177/00048690030393003>.

NATIONAL STATISTICS OFFICE THAILAND (NSOT). Time use survey. .Social Statistics Reports n.. S2-033. Bangkok: National Statistics Office Thailand, 2001. Disponível em: <http://web.nso.go.th/eng/stat/timeuse/time_use.htm>. 
PINHEIRO, L. S. Determinantes da alocação de tempo em trabalho reprodutivo: uma revisão sobre os achados em pesquisas nacionais e internacionais. In: FONTOURA, N.; ARAÚJO, C. (Eds.). Uso do tempo e gênero p. 61-99. Rio de Janeiro: UERJ, 2016.

RAMOS, D. Pesquisas de uso do tempo: um instrumento para aferir as desigualdades de gênero. In: BONETTI, A; ABREU, M. A. Faces da desigualdade de gênero e raça no Brasil. Brasília: Ipea, 2011.

RAO, V. M. Two decompositions of concentration ratio. Journal of the Royal Statistical Society. Series A (General), v. 132, n. 3, p. 418-425, 1969. Disponível em: <https://doi.org/10.2307/2344120>.

SOUTH, S. J.; SPITZE, G. Housework in marital and nonmarital households. American Sociological Review, v. 59, n. 3, p. 327, 1994. Disponível em: <https://doi. org/10.2307/2095937>.

SOUZA, A. As 24 horas do dia de um carioca. Relatório de Pesquisa. Rio de Janeiro, 15 Out. 1976.

TING, L.; MAlHOtRA, A. Disorders of sleep: an overview. Primary Care, v. 32, n. 2, p. 305-318, 2005. Disponível em: <https://doi.org/10.1016/j.pop.2005.02.004>.

UNITED STATES BUREAU OF LABOR STATISTICS (USBLS). American time use survey -2012 results (ATUS Results N. USDL-13-1178), p. 24. Washington (DC): USBLS, 2013.

VAN EVERY, J. Understanding gendered inequality: reconceptualizing housework. Women's Studies International Forum, v. 20, n. 3, p. 411-420, 1997. Disponível em: <https://doi.org/10.1016/S0277-5395(97)00024-1>. 
